\title{
INCIDENCE OF GASTRO-ESOPHAGEAL REFLUX DISEASE ASSOCIATED WITH TYPE 2 DIABETES
}

Sudarshan Tandukar ${ }^{1}$, Ansu Mali Joshi ${ }^{1}$

\section{ABSTRACT}

BACKGROUND: Gastro-Esophageal Reflux Disease is a growing problem with a reportedly increasing prevalence in type 2 diabetes patients. Despite this, study on the prevalence of Gastro-Esophageal Reflux Disease in Nepalese patients with type 2 diabetes is not available. The objective of this study is to determine the incidence of Gastro-Esophageal Reflux Disease in Nepalese patients with type 2 diabetes.

MATERIALAND METHODS: This cross-sectional study was carried out for a period of three months in patients with type 2 diabetes. A structured questionnaire "Frequency Scale for the Symptoms of GERD (FSSG)" was used for the evaluation of Gastro-Esophageal Reflux Disease in a total of Ninety Six (96) patients.

RESULTS: The incidence of Gastro-Esophageal Reflux Disease was observed in $22 \%$ of the patients with type 2 diabetes. The mean FSSG score in patients with Gastro-Esophageal Reflux Disease was 15.2 \pm 9.3 .

CONCLUSION: Gastro-Esophageal Reflux Disease is a common phenomenon in type 2 diabetes. Effective treatment along with proper glycemic control is essential so as to promote the Quality of Life of individuals.

KEY WORDS: Gastro-Esophageal Reflux Disease (GERD); Nepal; Type 2 diabetes

1. Department of Endocrinology, Alka Hospital Pvt. Ltd., Lalitpur, Nepal

For Correspondence

Mr. Sudarshan Tandukar, B.Pharm,

Department of Endocrinology,

Alka Hospital Pvt. Ltd.,

Lalitpur, Nepal

E-mail: sudarshantandukar@hotmail.com 


\section{INTRODUCTION}

Type 2 Diabetes (T2DM) is a chronic illness with numerous complications and the incidence of Gastro-Esophageal Reflux Disease (GERD) is common in diabetes. 'GERD, even though, does not result in significant morbidity or mortality, yet can substantially affect the Quality of Life (QOL) in diabetic patients.

Overall, numerous aspects can influence the occurrence of GERD in T2DM. A poor glycemic control itself has been associated with the presence of GI symptoms in T2DM. ${ }^{3}$ Similarly, a higher BMI is a significant risk factor for GERD. ${ }^{4}$ The association between the duration of diabetes and GERD, however, is still not clear.,

A study has reported that nearly $25 \%$ of patients with T2DM experienced GERD related symptoms. ${ }^{6}$ Another study conducted in Japanese population also showed similar results with a prevalence rate of $23 \% .^{7}$ As such, studies on the incidence of GERD in T2DM in the context of Nepalese diabetic population are absent. This study was thus conducted to determine the incidence of GERD in T2DM in Nepalese context.

\section{MATERIALAND METHODS}

The study was a hospital based cross sectional study, carried out in the Endocrine Unit of Alka Hospital, Nepal, for a period of three months from August to October, 2013. A total of 96 patients were enrolled in the study via a non-probability simple purposive sampling technique. Frequency Scale for the Symptoms of GERD (FSSG), a questionnaire specific to GERD, was used in order to diagnose GERD.

A written consent of each patient was obtained prior to the investigation. The T2DM patients visiting the Out-Patient Department, in the Endocrine Unit of Alka Hospital, Nepal were enrolled in this study. Exclusion criteria included patients with Type 1 diabetes, pregnant women or patients receiving acid suppression drugs (such as anti-histamines, proton pump inhibitors). Patients were also excluded if they had a history of esophageal or gastric surgery. The values are expressed as mean $\pm \mathrm{SD}$. The data was analyzed using Statistical Package for Social Sciences (SPSS), version 20.0.

The FSSG Questionnaire incorporated 12 questions, which were scored to specify the frequency of GI symptoms as: never $=0$; occasionally $=1$; sometimes $=2$; often $=3$; always $=$ 4. Patients with FSSG score greater than seven was considered positive to GERD. (When the cut-off point was set at eight, this test shows a sensitivity of $62 \%$, a specificity of $59 \%$ and an accuracy of $60 \%)^{8}$

\section{RESULTS}

\section{Characteristics of the patients enrolled in the study}

The highest number of patients $(n=96)$ was in the age-group 40 to 60 years, with a male/female ratio of sample population being 59/37. Body Mass Index (BMI) of $47 \%$ patients was in the normal range $\left(18.5\right.$ to $\left.24.9 \mathrm{~kg} / \mathrm{m}^{2}\right)$, followed by overweight group $(37 \%)$. The baseline characteristic of the study population is shown in Table 1.

Table 1: Baseline characteristics of study population

\begin{tabular}{|c|c|}
\hline Gender (Male/Female) & $59 / 37$ \\
\hline Mean Age ( $( \pm$ S.D.) years & $49.4 \pm 13.1$ \\
\hline Mean Duration of Onset of T2DM (years) & $4.7 \pm 6.2$ \\
\hline $\begin{array}{l}\text { Mean BMI }\left(\mathrm{kg} / \mathrm{m}^{2}\right) \\
\text { Underweight BMI }\left(<18.5 \mathrm{~kg} / \mathrm{m}^{2}\right) \\
\text { Normal BMI }\left(18.5 \text { to } 24.9 \mathrm{~kg} / \mathrm{m}^{2}\right) \\
\text { Overweight }\left(25.0 \text { to } 29.9 \mathrm{~kg} / \mathrm{m}^{2}\right) \\
\text { Obese }\left(>30 \mathrm{~kg} / \mathrm{m}^{2}\right)\end{array}$ & $\begin{array}{l}26.1 \pm 5.4 \\
2(2 \%) \\
46(44 \%) \\
36(35 \%) \\
15(16 \%)\end{array}$ \\
\hline Dyslipidemia* & 28 \\
\hline Hypertension** & 7 \\
\hline Hypertension and Dyslipidemia & 17 \\
\hline Mean Fasting Plasma Glucose level (mg/dL) & $142.8 \pm 64.1$ \\
\hline Mean Post Prandial Glucose level (mg/dL) & $203.9 \pm 85.7$ \\
\hline $\begin{array}{l}\text { Medications for diabetes } \\
\text { (Met/SU/ } \alpha \text { GI/DPP4I/Insulin) }\end{array}$ & $(85 / 51 / 12 / 9 / 14)$ \\
\hline
\end{tabular}

*Dyslipidemia was defined as a LDL-C $>100 \mathrm{mg} / \mathrm{dL}$, or patient on anti-hyperlipidemic medication

** Hypertension was defined as a Blood Pressure >140/90 $\mathrm{mmHg}$ or patient on anti-hypertensive medication

\section{FSSG Score}

Out of the total 96 patients with T2DM, the incidence of GERD (FSSG score $\geq 8$ ) was observed in $22 \%$ patients, with a mean FSSG score of $15.2 \pm 9.3$ (among the patients with GERD). The mean of dyspeptic symptoms and acid-reflux related symptoms in patients with GERD was observed to be $7.9 \pm 4.4$ and $7.2 \pm 8.8$.

\section{DISCUSSION}

This study has for the first time shown that the incidence of GERD in Nepalese with T2DM was $22 \%$. The incidence of GERD in Nepalese T2DM patients has been observed to be comparable with those in Japanese population where a prevalence of 23 to $25 \%$ was reported. ${ }^{6,7}$ However, a study in China reported that the prevalence of GERD in T2DM was approximately $16 \%$, which is lower than that in our study. ${ }^{9}$ The overall prevalence of GERD is relatively low in general Asian population (approximately 3 to $7 \%$ ). ${ }^{10}$ All previous studies have indicated T2DM as a possible risk factor for 
GERD. ${ }^{11}{ }^{12}$ Factors such as obesity, poor glucose control, dyslipidemia and peripheral neuropathy may all influence for the higher prevalence of GERD in T2DM patients. ${ }^{1,} 13,14$ Psychological distress could also be a cause of gastrointestinal symptoms in T2DM. ${ }^{15}$ Irrespective of the cause, the incidence of GERD has been observed to be rather high and requires attention.

There were few limitations in this study. Diagnosis of GERD was based on a simple questionnaire, while an endoscopic examination would have been more reliable for the purpose. A random sampling technique would have been more unbiased.

\section{CONCLUSION}

GERD is quiet common in Nepalese T2DM patients. Such a study had never before been conducted in Nepal. However, studies on a larger population are still more desirable. Nonetheless, an effective treatment of GERD along with adequate glycemic control is essential in order to improve the QOL of patients.

\section{REFERENCES}

1. Bytzer PM, Talley NJ, Leemon M, Young LJ, Jones MP, Horowitz M. Diabetes mellitus is associated with an increased prevalence of gastrointestinal symptoms: results from a population-based survey of 15,000 adults. Gastroenterology. 2000;118(4):A716. http://dx.doi.org/10.1016/S0016-5085(00)84995-1

2. Farup CE, Leidy NK, Murray M, Williams GR, Helbers L, Quigley EM. Effect of domperidone on the health-related quality of life of patients with symptoms of diabetic gastroparesis. Diabetes Care. 1998;21(10):1699-706.

http://dx.doi.org/10.2337/diacare.21.10.1699 PMid:9773734

3. Promberger $R$, Gadenstätter $M$, Ciovica $R$, Schwab $G$, Neumayer $C$. Gastroesophageal reflux disease in diabetic patients: a systematic review. European Surgery. 2007;39(6):340-54.

http://dx.doi.org/10.1007/s10353-007- 0366-9

4. Hampel H, Abraham NS, El-Serag HB. Meta-analysis: obesity and the risk for gastroesophageal reflux disease and its complications. Annals of Internal Medicine. 2005;143(3):199211.

http://dx.doi.org/10.7326/0003-4819-143-3-200508020-00006 PMid:16061918

5. Kase H, Hattori Y, Sato N, Banba N, Kasai K. Symptoms of gastroesophageal reflux in diabetes patients. diabetes research and clinical practice. 2008;79(2):e6-e7.

6. Nishida T, Tsuji S, Tsujii M, Arimitsu S, Sato T, Haruna Y, et al. Gastroesophageal reflux disease related to diabetes: analysis of 241 cases with type 2 diabetes mellitus. Journal of gastro enterology and hepatology. 2004;19(3):258-65. http://dx.doi.org/10.1111/j.1440-1746.2003.03288.x PMid:14748871

7. Hirata A, Kishida K, Nakatsuji H, Inoue K, Hiuge-Shimizu A, Funahashi $T$, et al. High prevalence of gastroesophageal reflux symptoms in type 2 diabetics with hypoadiponectinemia and metabolic syndrome. Nutr Metab (Lond). 2012;9(4). http://dx.doi.org/10.1186/1743-7075-9-4

8. Kusano M, Shimoyama Y, Sugimoto S, Kawamura O, Maeda M, Minashi $K$, et al. Development and evaluation of FSSG: frequency scale for the symptoms of GERD. Journal of gastroenterology. 2004;39(9):888-91. http://dx.doi.org/10.1007/s00535-004-1417-7 PMid:15565409

9. Sun H, Yi L, Wu P, Li Y, Luo B, Xu S. Prevalence of Gastroes ophageal Reflux Disease in Type II Diabetes Mellitus. Gastroenterology research and practice. 2014;2014.

10. Wong BC, Kinoshita Y. Systematic review on epidemiology of gastroesophageal reflux disease in Asia. Clinical gastroenterology and hepatology. 2006;4(4):398-407. http://dx.doi.org/10.1016/j.cgh.2005.10.011 PMid:16616342

11. Ariizumi K, Koike T, Ohara S, Inomata Y, Abe Y, Iijima K, et al. Incidence of reflux esophagitis and Helicobacter pylori infection in diabetic patients. World journal of gastroenterology: WJG. 2008;14(20):3212.

http://dx.doi.org/10.3748/wjg.14.3212 PMid:18506928 PMCid:PMC2712855

12. Horikawa A, Ishii-Nozawa R, Ohguro M, Takagi S, Ohtuji M, Yamada M, et al. Prevalence of GORD (gastro-oesophageal reflux disease) in Type 2 diabetes and a comparison of clinical profiles between diabetic patients with and without GORD. Diabetic Medicine. 2009;26(3):228-33.

http://dx.doi.org/10.1111/j.1464-5491.2009.02671.x PMid:19317816

13. Wang X, Pitchumoni C, Chandrarana K, Shah N. Increased prevalence of symptoms of gastroesophageal reflux diseases in type 2 diabetics with neuropathy. World journal of gastroenterology: WJG. 2008;14(5):709.

http://dx.doi.org/10.3748/wjg.14.709 PMid:18205259

PMCid:PMC2683996

14. Rubenstein JH, Morgenstern H, McConell D, Scheiman JM, Schoenfeld P, Appelman H, et al. Associations of diabetes mellitus, insulin, leptin, and ghrelin with gastroesophageal reflux and Barrett's esophagus. Gastroenterology. 2013;145(6):1237-44.e5.

15. Talley NJ, Bytzer P, Hammer J, Young L, Jones M, Horowitz M. Psychological distress is linked to gastrointestinal symptoms in diabetes mellitus. The American journal of gastroenterology. 2001;96(4):1033-8. http://dx.doi.org/10.1111/j.1572 0241.2001.03605.x PMid:11316143 